\title{
Efeito do período de coleta de urina, dos níveis de concentrado e de fontes protéicas sobre a excreção de creatinina, de uréia e de derivados de purina e a produção microbiana em bovinos Nelore $^{1}$
}

\section{Analívia Martins Barbosa ${ }^{2}$, Rilene Ferreira Diniz Valadares ${ }^{3}$, Sebastião de Campos Valadares Filho $^{4}$, Robson Magno Liberal Véras ${ }^{5}$, Maria Ignês Leão ${ }^{4}$, Edenio Detmann ${ }^{4}$, Mário Fonseca Paulino ${ }^{4}$, Marcos Inácio Marcondes ${ }^{6}$, Majorie Augusto de Souza ${ }^{6}$}

\author{
${ }^{1}$ Parte da tese apresentada à UFV para obtenção do título Magister Scientiae, parcialmente financiada CNPq/FAPEMIG. \\ 2 Doutoranda em Medicina Veterinária - UFV. \\ ${ }^{3}$ Departamento de Medicina Veterinária - UFV. \\ ${ }^{4}$ Departamento de Zootecnia - UFV. \\ 5 Universidade Federal Rural da Amazônia. \\ ${ }^{6}$ Mestrando em Zootecnia - UFV.
}

RESUMO - O efeito do período de coleta de urina sobre a excreção urinária de creatinina, uréia e derivados de purinas (DP), as purinas absorvidas e a produção de compostos nitrogenados microbianos (Nmic) foi avaliado em bovinos Nelore de quatro categorias: novilhas, machos castrados, machos não-castrados e vacas em lactação. A produção de Nmic obtida em amostras spot de urina foi comparada àquela obtida via coleta total. Dezesseis animais da raça Nelore mantidos em confinamento foram distribuídos em delineamento inteiramente casualizado em esquema de parcelas subdivididas, tendo nas parcelas os tratamentos em esquema fatorial $2 \times 4$ (dois níveis de concentrado, 25 ou 50\%, e quatro categorias de bovinos, novilhas, machos castrados, machos não-castrados e vacas em lactação) e nas subparcelas os seis dias de coleta. Não houve interação entre níveis de concentrado, categorias de animal e dias de coleta para as variáveis avaliadas. O volume urinário não foi influenciado pelos níveis de concentrado e os dias de coleta, contudo, foi significativamente maior para as vacas. A excreção de creatinina não foi afetada pelos tratamentos e dias de coletas, observando-se média de $27,1 \mathrm{mg} / \mathrm{kg}^{0,75}$. As purinas absorvidas e a produção de Nmic também não foram influenciadas pelos tratamentos e os dias de coleta. A produção de Nmic, estimada pela amostra spot de urina, não diferiu daquela obtida pela coleta total, nem entre os níveis de concentrado ou entre as categorias de animal. Concluiu-se que o período de coleta de urina de 24 horas é suficiente para experimentos utilizando animais Nelore, independentemente de serem novilhas, machos castrados ou não-castrados ou vacas, e que a coleta de amostra spot de urina também pode ser usada para estimar a produção de Nmic.

Palavras-chave: ácido úrico, alantoína, nutrição, ruminantes

\section{Effect of urinary collection days, concentrate levels and protein sources on creatinine, urea and purine derivatives excretions and microbial protein synthesis in Nellore cattle}

\footnotetext{
ABSTRACT - The effects of collection days on urinary excretion of creatinine and purine derivatives (PD), absorbed purines and microbial $\mathrm{N}$ synthesis (Nmic) were evaluated in different categories of Nellore cattle: heifers, steers, bulls and lactating cows. Yield of Nmic estimated from spot urine samples was compared to that obtained by total urine collection. Sixteen feedlot Nellore animals were assigned to a completely randomized design in a split plot scheme with treatments (two levels of concentrate [ 25 or $50 \%$ ] and four categories [heifers, steers, bulls and lactating cows] included in the plots $(2 \times 4$ factorial arrangement) and collection days (six days) in the sub-plots. No significant interactions among concentrate levels, animal categories and collection days were observed. In addition, urinary volume was not affected by concentrate levels and collection days, although a significant effect was observed for cows. Neither treatments nor collection days significantly affected urinary excretion of creatinine that averaged $27.1 \mathrm{mg} / \mathrm{kg}^{0.75}$. Similar results were observed for absorbed purines and Nmic production. Production of Nmic estimated by spot urine sample did not differ from that obtained by total collection. The estimation of Nmic also was not affected by concentrate levels and animal category. It was concluded that 24-h urinary collection period is recommended for Nellore cattle and that was independent of animal category (heifers, steers, bulls and lactating cows) Therefore, spot urine samples can be used to estimate microbial protein synthesis.
}

Key Words: uric acid, allantoin, nutrition, ruminants 


\section{Introdução}

Em ruminantes, o aporte de aminoácidos no duodeno é originário da proteína microbiana sintetizada no rúmen, da proteína do alimento que não foi degradada no rúmen e da proteína endógena (descamações celulares, sucos digestivos, entre outros). A proteína microbiana constitui, geralmente, uma proporção considerável do fluxo duodenal de nitrogênio $(\mathrm{N})$ aminoacídico nos ruminantes, podendo alcançar 100\% em determinadas situações (NRC, 1996), o que denota a importância do estudo dos mecanismos de síntese protéica microbiana. Então, a determinação da contribuição da proteína microbiana para o animal é importante e sua estimação está incorporada aos sistemas de avaliação de proteína adotados em diversos países.

Considerando que o objetivo básico nos estudos de alimentação de ruminantes é maximizar a síntese de proteína microbiana, em virtude de seu excelente balanceamento de aminoácidos (Valadares Filho \& Valadares, 2001), torna-se fundamental o estudo de métodos para estimar a produção de proteína microbiana de forma rápida, rotineira e não invasiva.

As pesquisas ao longo dos últimos anos confirmaram a relação entre produção de proteína microbiana e excreção urinária de derivados de purinas (Perez et al., 1996).

Chen \& Gomes (1992) afirmaram que, para reduzir erros atribuídos a variações na produção urinária, as coletas de urina deveriam ser feitas durante pelo menos cinco dias. Entretanto, de acordo com Fleming et al. (1991), período de coleta com duração de 24 horas poderia ser representativo da produção urinária. Valadares et al. (1997) sugeriram que amostras representativas de urina poderiam ser obtidas por período de 24 horas. Contudo, há necessidade de se validar o uso da coleta de 24 horas de duração, haja vista o número reduzido de informações para bovinos Nelore.

Além da utilização do método não invasivo para medir a produção de proteína microbiana utilizando coletas de urina com duração de 24 horas, outro grande avanço é a possibilidade de se estimar o volume urinário com uma única amostra de urina, denominada amostra spot, geralmente obtida quatro horas após a alimentação, conforme descrito por Valadares et al. (1999).

A estimação do volume urinário de 24 horas obtida a partir de amostra spot baseia-se na relativa constância da excreção de creatinina, descrita por Palmer et al. (1914), citados por Ørskov \& Macleod (1982).

A excreção de creatinina é relativamente constante em função do peso vivo pelo fato de ser pouco ou não afetada por fatores dietéticos. Essa determinação torna possível a simplificação de métodos que requerem a coleta total de urina. Utilizando-se a concentração de creatinina na urina como indicador da produção urinária, pode-se estimar a excreção dos derivados de purina e de outros compostos nitrogenados (Chen et al., 1995; Rennó et al., 2000; Oliveira et al., 2001; Silva et al., 2001; Rennó et al., 2003)

Assim, objetivou-se avaliar o efeito do período de coleta de urina sobre a excreção urinária de creatinina, uréia e derivados de purinas, as purinas absorvidas e a produção de compostos nitrogenados microbianos (Nmic) em bovinos Nelore de quatro categorias (novilhas, machos castrados, machos inteiros e vacas em lactação) alimentados com dietas contendo 25 ou $50 \%$ de concentrado na base da matéria seca total. Comparou-se também a produção de Nmic obtida em amostras spot de urina àquela obtida via coleta total urinária.

\section{Material e Métodos}

O experimento foi conduzido no Laboratório de Animais e no Laboratório de Nutrição Animal do Departamento de Zootecnia do Centro de Ciências Agrárias da Universidade Federal de Viçosa, em Viçosa, MG.

Foram utilizados 16 animais zebuínos da raça Nelore, sendo quatro de cada categoria: machos castrados, machos inteiros, novilhas e vacas lactantes (no período final de lactação). Todos os animais, com exceção das vacas, foram fistulados no rúmen e no duodeno e alojados em baias individuais $\left(9 \mathrm{~m}^{2}\right)$ cobertas, com piso de concreto revestido de borracha, providas de comedouros de alvenaria e de bebedouros individuais.

Os 16 bovinos Nelore foram distribuídos em delineamento inteiramente casualizado, em esquema de parcelas subdivididas, tendo nas parcelas os tratamentos arranjados em fatorial $2 \times 4$ - dois níveis de concentrado ( 25 ou $50 \%$ ) e quatro categorias animais (novilhas, machos castrados, machos não-castrados e vacas lactantes, com pesos médios de 243, 265, 226 e 467, respectivamente-e nas subparcelas, os seis dias de coletas.

O experimento foi realizado em dois períodos, cada um com duração de 20 dias, sendo 14 dias de adaptação às dietas e seis dias para as coletas. As dietas foram constituídas de silagem de milho e concentrado nas proporções de 25 ou $50 \%$, com base na matéria seca (MS), e foram balanceadas de acordo com o NRC (1996), para conter aproximadamente $12 \%$ de PB. Os concentrados foram formulados com milho, uréia, farelo de algodão com $38 \%$ de proteína bruta (PB) e mistura mineral. 
Nos períodos 1 e 2, foram oferecidas a todos os animais as dietas com 25 e $50 \%$ de concentrado na base da matéria seca, respectivamente. A alimentação foi fornecida duas vezes ao dia, sempre às 8 e 16h, na forma de ração completa, à vontade, permitindo-se sobras de, no máximo, $10 \%$.

Nas Tabelas 1 e 2 podem ser visualizadas a proporção dos ingredientes na mistura dos concentrados e a composição química das dietas, respectivamente, ressaltando-se a composição da silagem de milho nos períodos 1 (P1) e 2 (P2).

Diariamente, foram registradas as quantidades dos alimentos fornecidos e das sobras de cada animal, para a estimativa do consumo, e, durante o período experimental, foram realizadas amostragens das dietas e sobras. Para as sobras diárias de cada animal, foi feita uma amostra composta. Todas as amostras foram acondicionadas em sacos plásticos e congeladas para análises posteriores.

Tabela 1 - Proporção dos ingredientes nos concentrados (\% matéria natural)

Table 1 - Ingredient composition of the concentrates (as-fed basis)

\begin{tabular}{lcc}
\hline Item & \multicolumn{2}{c}{$\begin{array}{c}\text { Nível de concentrado } \\
\text { Concentrate level }\end{array}$} \\
\cline { 2 - 3 } & $25 \%$ & $50 \%$ \\
\hline $\begin{array}{l}\text { Milho } \\
\text { Corn }\end{array}$ & 58,90 & 83,20 \\
$\begin{array}{l}\text { Farelo de algodão 38\% } \\
\text { Cottonseed meal 38\% }\end{array}$ & 33,90 & 13,20 \\
$\begin{array}{l}\text { Uréia/Sulfato de amônia } \\
\begin{array}{l}\text { Urea/ammonium sulphate } \\
\text { Cloreto de sódio }\end{array}\end{array}$ & 3,00 & 1,50 \\
$\begin{array}{l}\text { Sodium chloride } \\
\text { Mistura mineral* }\end{array}$ & 1,10 & 0,55 \\
$\begin{array}{l}\text { Mineral mix } \\
\text { Calcário }\end{array}$ & 1,10 & 0,55 \\
Limestone & 2,00 & 1,00 \\
\hline
\end{tabular}

* Ca 240 g, I 90 mg, P 174 g, Mn 2.000 mg, Zn 5.270 mg, Se 15 mg, Co $100 \mathrm{mg}, \mathrm{F}$ (max.) $1.740 \mathrm{mg}, \mathrm{Cu} 1.250 \mathrm{mg}$, veículo q.s.p $1000 \mathrm{~g}, \mathrm{Fe}$ $1.795 \mathrm{mg}$, por kilo do produto puro em elementos ativo.
As coletas totais de urina de cada animal foram realizadas diariamente, do 15 a a $20^{\circ}$ - dia de cada período, utilizando-se sondas de Folley 22 ou 26, duas vias, com balão de $30 \mathrm{~mL}$ para novilhas e $60 \mathrm{~mL}$ para vacas, respectivamente. Na extremidade livre do cateter, foi adaptada mangueira de polietileno, pela qual a urina foi conduzida até um recipiente de plástico com tampa, que continha $200 \mathrm{~mL}$ de $\mathrm{H}_{2} \mathrm{SO}_{4}$ a $20 \%$. A urina dos machos foi coletada utilizando-se funis adaptados aos animais e ligados a mangueiras de polietileno, que conduziam a urina até um galão plástico que continha $200 \mathrm{~mL} \mathrm{de}_{2} \mathrm{SO}_{4}$ a $20 \%$.

Ao término de cada período de 24 horas de coleta, a urina foi pesada, homogeneizada e amostrada. Foram feitas duas amostras: uma em que $10 \mathrm{~mL}$ de urina foram diluídos em $40 \mathrm{~mL}$ de $\mathrm{H}_{2} \mathrm{SO}_{4} \quad 0,036 \mathrm{~N}$ para posteriores análises de alantoína e ácido úrico e outra de $50 \mathrm{~mL}$ para análises de creatinina e uréia, ambas armazenadas em frascos plásticos a $-15^{\circ} \mathrm{C}$.

Quatro horas após o fornecimento da ração, no $16^{0}$ dia de cada período experimental, foi coletado o sangue de todos os animais, via punção da veia jugular, utilizando-se tubo de ensaio contendo gel separador e acelerador de coagulação.As amostras foram imediatamente centrifugadas a $5.000 \mathrm{rpm}$ por 15 minutos, obtendo-se o soro sangüíneo, que foi armazenado a $-15^{\circ} \mathrm{C}$, para análise de uréia.

Amostras spot de urina foram obtidas de todos os animais, no $20^{\circ}$ dia do período experimental, aproximadamente quatro horas após a alimentação, durante micção espontânea e foram processadas da mesma forma que aquelas referentes às coletas com 24 horas de duração.

As concentrações de uréia e creatinina foram estimadas na urina e no plasma sangüíneo utilizando-se kits comerciais (Labtest). As análises de alantoína e de ácido úrico na urina foram feitas pelo método colorimétrico, conforme Fujihara et al. (1987).

Tabela 2 - Composição química das dietas experimentais (com base na matéria seca)

Table 2 - Chemical composition of the experimental diets (dry matter basis)

\begin{tabular}{|c|c|c|c|c|c|c|}
\hline \multirow[t]{2}{*}{$\begin{array}{l}\text { Item } \\
\text { Item }\end{array}$} & \multicolumn{2}{|c|}{$\begin{array}{l}\text { Silagem de milho } \\
\text { Corn silage }\end{array}$} & \multicolumn{2}{|c|}{$\begin{array}{l}\text { Concentrado } \\
\text { Concentrate }\end{array}$} & \multicolumn{2}{|c|}{$\begin{array}{l}\text { Dieta total } \\
\text { Total diet }\end{array}$} \\
\hline & P 1 & P 2 & $25 \%$ & $50 \%$ & $25 \%$ & $50 \%$ \\
\hline $\mathrm{MO}^{1}(O M, \%)$ & 92,10 & 91,40 & 95,65 & 95,14 & 93,00 & 93,26 \\
\hline $\mathrm{PB}^{1}(C P)$ & 7,40 & 7,20 & 28,50 & 17,50 & 12,70 & 12,40 \\
\hline $\mathrm{EE}^{1}$ & 3,40 & 3,40 & 2,40 & 3,10 & 3,15 & 3,25 \\
\hline
\end{tabular}

${ }_{1} \mathrm{MS}=$ matéria seca; $\mathrm{MO}=$ matéria orgânica; $\mathrm{PB}=$ proteína bruta; $\mathrm{EE}$ = extrato etéreo; FDN = fibra em detergente neutro; CNF = carboidratos não-fibrosos; $\mathrm{P} 1$ = período um; $\mathrm{P} 2$ = período dois.

${ }^{1} D M=$ dry matter; $O M=$ organic matter; $C P=$ crude protein; $E E=$ ether extract; $N D F=$ neutral detergent fiber; NFC = nonfiber carbohydrates; $P 1=$ period one; $P 2=$ period two. 
A excreção total de derivados de purina foi calculada pela soma das quantidades de alantoína e ácido úrico excretadas na urina, expressas em $\mathrm{mmol} / \mathrm{dia}$.

As purinas absorvidas em ( $\mathrm{Y}, \mathrm{mmol} / \mathrm{dia})$ foram calculadas a partir da excreção de derivados de purina (X, mmol/dia), por intermédio da equação:

$$
\mathrm{Y}=\frac{\mathrm{X}-0,385 \mathrm{PV}^{0,75}}{0,85}
$$

em que 0,85 é a recuperação de purinas absorvidas como derivados de purina e $0,385 \mathrm{PV}^{0,75}$, a contribuição endógena para a excreção de purinas (Chen \& Gomes, 1992).

A síntese ruminal de compostos nitrogenados ( $\mathrm{Y}, \mathrm{g} \mathrm{N} / \mathrm{dia})$ foi calculada em função das purinas absorvidas ( $\mathrm{X}, \mathrm{mmol} / \mathrm{dia}$ ), pelaequaçãodeChen\& Gomes(1992): $Y=70 X / 0,83 \times 0,116 \times 1000$, em que 70 é o conteúdo de $\mathrm{N}$ de purinas ( $\mathrm{mg} \mathrm{N} / \mathrm{mol}), 0,116$ a relação $\mathrm{N}$ purina : $\mathrm{N}$ total nas bactérias e 0,83 a digestibilidade das purinas microbianas.

O volume urinário estimado a partir das amostras spot foi calculado pela excreção média de creatinina, encontrada no experimento, em miligrama por quilo de peso vivo $(\mathrm{mg} / \mathrm{kg} \mathrm{PV})$, dividida pela concentração na amostra spot de urina.

O experimento foi analisado segundo o modelo:

$$
\begin{aligned}
\mathrm{Y}_{\mathrm{ijk}}=\mu+\mathrm{D}_{\mathrm{i}}+\mathrm{G}_{\mathrm{j}}+\mathrm{DG}_{\mathrm{ij}} & +\mathrm{E}_{\mathrm{ij}}+\mathrm{C}_{\mathrm{k}}+\mathrm{DC}_{\mathrm{ik}}+\mathrm{GC}_{\mathrm{jk}}+\mathrm{DGC}_{\mathrm{ijk}} \\
& +\sum_{\mathrm{ijk}}
\end{aligned}
$$

em que: $\mu=$ constante geral; $D_{i}=$ efeito relativo à dieta $\mathrm{i}$; $\mathrm{G}_{\mathrm{j}}=$ efeito relativo à categoria animal $\mathrm{j} ; \mathrm{E}_{\mathrm{ij}}=$ efeito residual das parcelas; $C_{k}=$ efeito relativo ao dia de coleta $k ; \mathrm{DG}_{\mathrm{ij}}$, $\mathrm{DC}_{\mathrm{ik}}, \mathrm{GC}_{\mathrm{jk}}, \mathrm{DGC}_{\mathrm{ijk}}=$ interações sobre efeitos principais; e $\Sigma_{\mathrm{ijk}}=$ erro aleatório, pressuposto $\operatorname{NID}\left(0 ; \sigma^{2}\right)$.

As análises foram realizadas por intermédio do programa Statistical Analysis System, versão 8.2 (SAS, 2001), e as médias, quando pertinentes, foram comparadas pelo teste Tukey a $5 \%$ de probabilidade.

\section{Resultados e Discussão}

Na Tabela 3 são apresentadas as médias de volume urinário e excreção de creatinina na urina, em mg/kg PV, $\mathrm{mg} / \mathrm{kg} \mathrm{PV}^{0,75}$ e mmol $/ \mathrm{kg} \mathrm{PV}^{0,75}$, obtidas em função dos níveis de concentrado, das categorias e dos dias de coleta. Não houve interação $(P>0,05)$ entre níveis de concentrado, categorias e dias de coleta para nenhuma das variáveis analisadas. $\mathrm{O}$ volume urinário não foi influenciado $(\mathrm{P}>0,05)$ pelos níveis de concentrado e os dias de coleta, contudo, foi significativamente maior $(\mathrm{P}<0,05)$ para as vacas em lactação. O maior volume de urina das vacas pode ser explicado pelo seu maior peso vivo e, conseqüentemente, pelo maior consumo de MS e água.

A ausência de efeito dos dias de coleta sobre a excreção diária de creatinina está de acordo com as observações descritas por Valadares et al. (1997), que não encontraram diferenças nas excreções de creatinina obtidas durante 12 , 24,48 ou 72 horas de coleta. Também Chizzotti et al. (2004a) não observaram efeito da duração do período de coleta de urina $(6,12,18$ ou 24 horas) sobre a excreção de creatinina.

Foi encontrada excreção diária média de $27,1 \mathrm{mg} / \mathrm{kg}$ PV de creatinina na urina, que se aproxima daquelas descritas por Rennó et al. (2000) e Rennó et al. (2003), para novilhos de vários grupos genéticos (27,36 e 27,78, respectivamente). Para vacas de leite, as excreções diárias de creatinina variam de 29 (Valadares et al., 1999), 24,04 e 24,07 (Chizzotti et al., 2004a), 23,41 (Oliveira et al., 2001) e 23,60 mg/kg PV (Silva et al., 2001). Todos os autores mencionaram que a excreção média diária de creatinina não foi influenciada por diferentes tratamentos.

A ausência de efeito dos dias de coleta sobre a excreção de creatinina permite sugerir que um período de coleta de urina com duração de 24 horas é suficiente para medir a excreção de creatinina em animais Nelore. Períodos mais curtos de coleta de urina são desejáveis, pois reduzem o tempo experimental e, conseqüentemente, o custo e o desconforto animal, decorrentes da utilização de sondas nas fêmeas e de funis coletores nos machos.

As excreções urinárias médias de alantoína e de purinas totais, as quantidades de purinas absorvidas, em mmol/dia, e as estimativas da produção de compostos nitrogenados microbianos (Nmic), em g N/dia, para os dois níveis de concentrado ( $25 \%$ e $50 \%$ na MS total das dietas), as quatro categorias de Nelore e os seis dias de coleta são apresentadas na Tabela 4. Não houve interação $(P>0,05)$ entre níveis de concentrado, categorias e dias de coleta de urina.

$\mathrm{O}$ aumento do nível de concentrado reduziu $(\mathrm{P}<0,05)$ a excreção de alantoína, mas não alterou $(\mathrm{P}>0,05)$ a produção de Nmic. A excreção urinária de alantoína foi maior $(\mathrm{P}<0,05)$ para as vacas, enquanto as excreções de derivados de purina e as quantidades de purinas absorvidas e a produção de Nmic foram somente numericamente maiores para as vacas. Possivelmente, essa maior produção de Nmic seja conseqüência do maior consumo de matéria seca observado para as vacas $(4,56 ; 5,44 ; 4,09 \mathrm{e} 10,65 \mathrm{~kg} / \mathrm{dia}$, respectivamente, para novilhas, machos castrados, machos inteiros e vacas).

Não houve efeito $(\mathrm{P}>0,05)$ dos dias de coleta de urina sobre nenhuma das variáveis analisadas, o que permite 
874 Efeito do período de coleta de urina, dos níveis de concentrado e de fontes protéicas sobre a excreção de creatinina...

Tabela 3 - Média e erro-padrão (EP) de volume urinário (L) e excreção de creatinina, em mg/kg PV, mg/kg $\mathrm{kg}^{0,75}, \mathrm{mmol}^{\mathrm{kgg}}{ }^{0,75}, \mathrm{obtidos}$ com dois níveis de concentrado, quatro categorias e seis dias de coleta

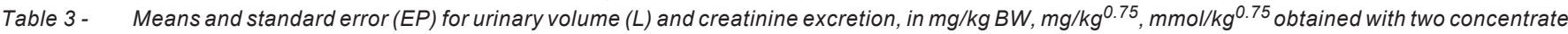
levels, four animal category and six collection days

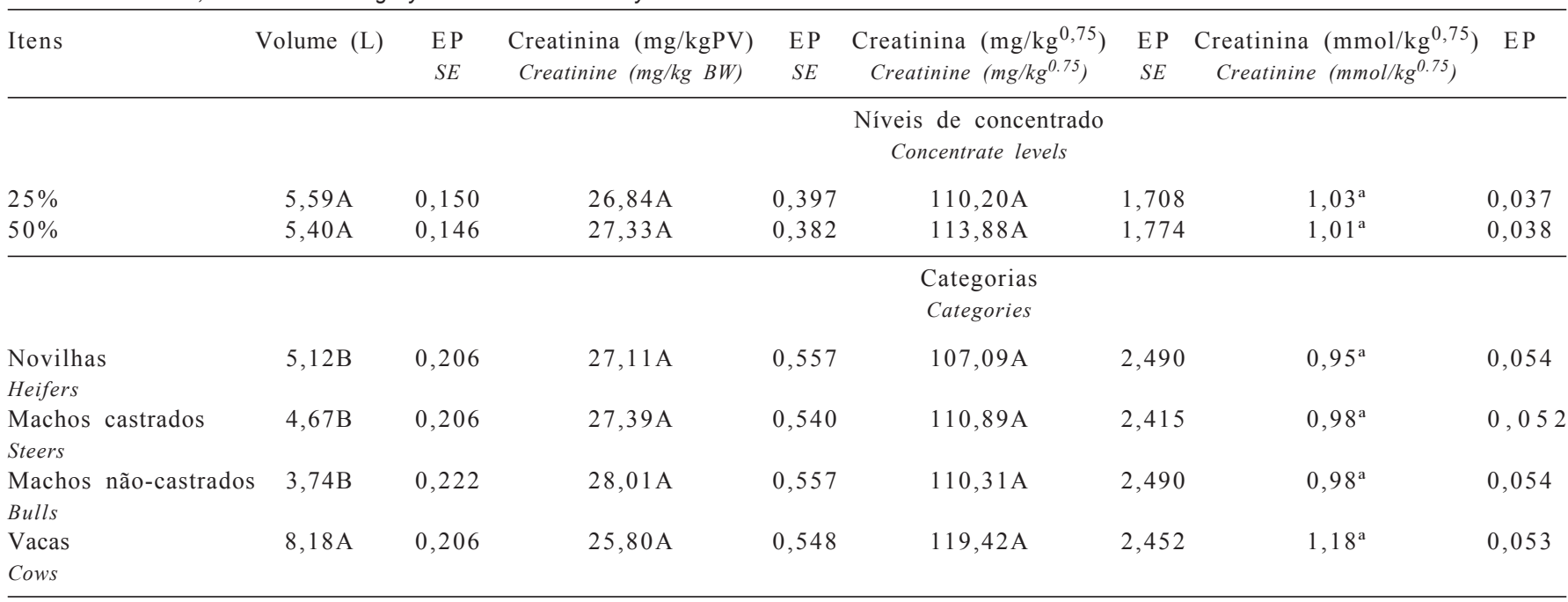

\begin{tabular}{|c|c|c|c|c|c|c|c|c|}
\hline \multirow[b]{2}{*}{1} & \multirow[b]{2}{*}{$5,58 \mathrm{~A}$} & \multicolumn{7}{|c|}{$\begin{array}{l}\text { Dias de coleta } \\
\text { Collection days }\end{array}$} \\
\hline & & 0,258 & $27,17 \mathrm{~A}$ & 0,772 & $109,74 \mathrm{~A}$ & 3,231 & $0,97 \mathrm{~A}$ & 0,070 \\
\hline 2 & $5,54 \mathrm{~A}$ & 0,249 & $27,66 \mathrm{~A}$ & 0,656 & $115,84 \mathrm{~A}$ & 2,937 & $1,03 \mathrm{~A}$ & 0,063 \\
\hline 3 & $5,39 \mathrm{~A}$ & 0,263 & $27,37 \mathrm{~A}$ & 0,595 & $112,59 \mathrm{~A}$ & 2,662 & $1,00 \mathrm{~A}$ & 0,057 \\
\hline 4 & $5,28 \mathrm{~A}$ & 0,254 & $27,63 \mathrm{~A}$ & 0,687 & $113,83 \mathrm{~A}$ & 3,073 & $1,01 \mathrm{~A}$ & 0,066 \\
\hline 5 & $5,82 \mathrm{~A}$ & 0,254 & $27,16 \mathrm{~A}$ & 0,687 & $112,59 \mathrm{~A}$ & 3,073 & $1,00 \mathrm{~A}$ & 0,066 \\
\hline 6 & $5,30 \mathrm{~A}$ & 0,263 & $25,17 \mathrm{~A}$ & 0,722 & $105,87 \mathrm{~A}$ & 3,231 & $1,15 \mathrm{~A}$ & 0,070 \\
\hline
\end{tabular}

Médias, na coluna, seguidas de letras iguais não diferem $(P>0,05)$ pelo teste Tukey.

Means, in a column, followed by the same letters do not differ $(P>0.05)$ by Tukey test.

sugerir que a coleta total de urina durante 24 horas é suficiente para estimar a produção de Nmic em animais Nelore, independentemente de serem novilhas, machos castrados ou inteiros e vacas em lactação.

Neste experimento, as excreções urinárias de alantoína foram 77,34 e $60,12 \mathrm{mmol} /$ dia para os níveis de 25 e $50 \%$ de concentrado, respectivamente, valores inferiores aos registrados para vacas leiteiras, de 211 a $571 \mathrm{mmol} / \mathrm{dia}, 191,5$ $\mathrm{mmol} /$ dia e 179,75 a 284,56 mmol/dia, por Gonda \& Lindberg (1997), Johnson et al. (1998) e Silva et al. (2001), respectivamente. Estes resultados descritos na literatura indicam que o nível de alantoína em vacas não é constante em todos os estádios fisiológicos e tratamentos dietéticos, o que parece acontecer também em vacas zebuínas.

O valor médio de 33,10 gN/dia para a produção de Nmic, obtido para a dieta com $50 \%$ de concentrado, foi numericamente inferior à média de $47,48 \mathrm{gN} /$ dia encontrada para dietas contendo $25 \%$ de concentrado. Os valores encontrados são inferiores aos obtidos por Rennó et al. (2000), que, agrupando cinco experimentos envolvendo animais mestiços e nelores, obtiveram comportamento quadrático para as excreções de derivados de purina urinários em função dos níveis de concentrado da ração (20 a 75\%), registrando-se valores máximos de 72,07 e 86,08 g de Nmic/dia, para os níveis de 62,91 e $63,60 \%$ de concentrado, respectivamente, dependendo do método de cálculo. Entretanto, a produção média obtida nesse experimento $(40,29 \mathrm{gN} / \mathrm{dia})$ foi aproximadamente $22 \%$ maior que a relatada por Rennó et al. (2003), em estudo com animais zebuínos $(31,29 \mathrm{gN} / \mathrm{dia})$ de diferentes grupos genéticos (Holandês; 1/2Hol-Guz; 1/2 Hol-Gir e Zebu).

$\mathrm{Na}$ Tabela 5 podem ser observadas as médias e os errospadrão das médias da produção de compostos nitrogenados microbianos (Nmic), expressa em $\mathrm{gN} / \mathrm{dia}$, obtidos pela coleta total de urina nos dois níveis de concentrado e nas quatro categorias animais. Na mesma tabela, são apresentadas as médias da produção de Nmic obtidas pela coleta total de urina e pela estimativa via coleta spot. Não houve diferença $(\mathrm{P}>0,05)$ significativa para nenhuma das variáveis avaliadas.

A ausência de diferença significativa para a produção de Nmic obtida pelas coletas total e spot de urina também foi verificada por Silva et al. (2001), trabalhando com vacas leiteiras e por Rennó et al. (2003), para diferentes grupos genéticos. Chen et al. (1995) relataram que a amostra spot de urina pode não ter representatividade suficiente para a comparação de diferentes tratamentos em ovinos. 
Tabela 4 - Média das excreções urinárias de alantoína e purinas totais, purinas absorvidas e estimativa da produção de compostos nitrogenados microbianos (Nmic), obtida com dois níveis de concentrado, quatro categorias e seis dias de coleta

Table 4 - Means for the urinary excretions of allantoin and total purine, absorbed purine and estimated microbial nitrogen synthesis (Nmic) obtained with two concentrate levels, four animal categories and six collection days

Alantoína (mmol/dia) Purinas totais (mmol/dia) Purinas absorvidas (mmol/dia) Nmic(gN/dia)

Allantoin Total purines Absorbed purines

\begin{tabular}{|c|c|c|c|c|}
\hline \multirow{2}{*}{$\begin{array}{l}25 \% \\
50 \%\end{array}$} & \multicolumn{4}{|c|}{$\begin{array}{l}\text { Níveis de concentrado } \\
\text { Concentrate levels }\end{array}$} \\
\hline & $77,34 \mathrm{~A}$ & $82,83 \mathrm{~A}$ & $65,32 \mathrm{~A}$ & $47,48 \mathrm{~A}$ \\
\hline & \multicolumn{4}{|c|}{$\begin{array}{l}\text { Categorias } \\
\text { Categories }\end{array}$} \\
\hline Machos não-castrados (Bulls) & $58,73 \mathrm{~B}$ & $62,66 \mathrm{~B}$ & $45,87 \mathrm{~A}$ & $33,35 \mathrm{~A}$ \\
\hline \multirow[t]{2}{*}{ Vacas (Cows) } & $92,33 \mathrm{~A}$ & $102,16 \mathrm{~A}$ & $74,79 \mathrm{~A}$ & $54,38 \mathrm{~A}$ \\
\hline & \multicolumn{4}{|c|}{$\begin{array}{l}\text { Dias de coleta } \\
\text { Collection days }\end{array}$} \\
\hline 1 & $66,40 \mathrm{~A}$ & $71,38 \mathrm{~A}$ & $51,26 \mathrm{~A}$ & $37,28 \mathrm{~A}$ \\
\hline 6 & $65,40 \mathrm{~A}$ & $70,28 \mathrm{~A}$ & $49,98 \mathrm{~A}$ & $36,34 \mathrm{~A}$ \\
\hline CV (\%) & 12,14 & 16,77 & 26,18 & 26,17 \\
\hline
\end{tabular}

Médias, na coluna, seguidas de letras iguais não diferem $(P>0,05)$ pelo teste Tukey.

Means, in a column, followed by the same letters do not differ $(P>0.05)$ by Tukey test.

Tabela 5 - Médias e erro-padrão da média (EPM) para a estimativa da produção de compostos nitrogenados microbianos (Nmic - gN/dia) em dois níveis de concentrado e quatro categorias animais, obtidos com uma coleta total de urina e pelos dois métodos de coleta de urina (total e spot)

Table 5 - $\quad$ Means and standard error of the mean for estimated microbial nitrogen synthesis ( $\mathrm{Nmic}$ - gN/d) obtained with two concentrate levels and four animal categories by either urinary total collection or by both urinary collection methods (total and spot)

\begin{tabular}{lcc}
\hline Item & Nmic & EPM \\
Item & & $S E M$ \\
\hline
\end{tabular}

Níveis de concentrado (Concentrate levels)

\begin{tabular}{rrr}
$25 \%$ & $46,87 \mathrm{~A}$ & 2,632 \\
$50 \%$ & $37,74 \mathrm{~A}$ & 3,283 \\
\hline
\end{tabular}

Categorias (Categories)

Novilhas (Heifers)

Machos castrados (Steers)

Machos não-castrados (Bulls)

Vacas (Cows)

$\begin{array}{ll}36,29 \mathrm{~A} & 3,722 \\ 30,63 \mathrm{~A} & 3,722 \\ 48,98 \mathrm{~A} & 4,924 \\ 66,31 \mathrm{~A} & 4,404\end{array}$

Métodos de coleta (Collection methods)

\begin{tabular}{lll} 
Coleta total (Total collection) & $44,96 \mathrm{~A}$ & 2,904 \\
Coleta spot (Spot collection) & $41,64 \mathrm{~A}$ & 2,904 \\
\hline
\end{tabular}

Médias, na coluna, seguidas de letras iguais não diferem $(P>0,05)$ pelo teste Tukey.

Means, in a column, followed by the same letters do not differ $(P>0.05)$ by Tukey test.

Constam na Tabela 6 as excreções médias de uréia, em $\mathrm{mg} / \mathrm{kg} \mathrm{PV}$, para os dois níveis de concentrado e as quatro categorias animais. Houve interação $(\mathrm{P}<0,05)$ entre níveis
Tabela 6 - Média de excreção de uréia na urina, em mg/kg PV, de acordo com os níveis de concentrado e as categorias animais

Table 6 - $\quad$ Means of urinary urea excretion, in $\mathrm{mg} / \mathrm{kg} \mathrm{BW}$, according to two concentrate levels and four animal categories

\begin{tabular}{llcccc}
\hline $\begin{array}{l}\text { Nível de } \\
\text { concentrado }\end{array}$ & \multicolumn{4}{c}{$\begin{array}{c}\text { Categoria } \\
\text { Category }\end{array}$} & \\
\cline { 2 - 5 } $\begin{array}{l}\text { Concentrate } \\
\text { level }\end{array}$ & $\begin{array}{c}\text { Novilhas } \\
\text { Heifers }\end{array}$ & $\begin{array}{c}\text { Machos } \\
\text { castrados } \\
\text { Steers }\end{array}$ & $\begin{array}{c}\text { Machos } \\
\text { não-castrados } \\
\text { Bulls }\end{array}$ & $\begin{array}{c}\text { Vacas } \\
\text { Cows }\end{array}$ & \\
\hline $25 \%$ & $209,61 \mathrm{Ba}$ & $197,09 \mathrm{Aa}$ & $187,55 \mathrm{Aa}$ & $266,27 \mathrm{Aa}$ & \\
& & & & & 11,23 \\
$50 \%$ & $306,02 \mathrm{Aa}$ & $212,92 \mathrm{Ab}$ & $226,88 \mathrm{Aab}$ & $219,11 \mathrm{Ab}$ & \\
\hline
\end{tabular}

${ }^{1}$ Coeficiente de variação (Coefficient of variation).

Letras maiúsculas comparam médias nas colunas e letras minúsculas, nas linhas. Médias seguidas de letras iguais não diferem $(P>0,05)$ pelo teste Tukey.

Capital letters compare means in the columns and small letters in the rows. Means, in a column or in a row, followed by the same letters do not differ $(P>0.05)$ by Tukey test.

de concentrado e categorias para a excreção urinária de uréia. Para o nível de $25 \%$ de concentrado, não houve diferença $(\mathrm{P}>0,05)$ entre as categorias. Contudo, para o nível de $50 \%$ de concentrado, as excreções de uréia foram maiores $(\mathrm{P}<0,05)$ nas novilhas.

Avaliando cada categoria de Nelore, observou-se que somente as novilhas apresentaram maior $(\mathrm{P}<0,05)$ excreção de uréia no maior nível de concentrado oferecido $(50 \%) \mathrm{em}$ relação às demais categorias. 
876 Efeito do período de coleta de urina, dos níveis de concentrado e de fontes protéicas sobre a excreção de creatinina...

Tabela 7 - Médias de N-Uréia ( $\mathrm{mg} / \mathrm{dL}$ ) no soro sangüíneo, de acordo com os níveis de concentrado e as categorias animais

Table 7 - Means of $\mathrm{N}$-urea ( $\mathrm{mg} / \mathrm{dL}$ ) in the blood serum, according to two concentrate levels and four animal categories

\begin{tabular}{|c|c|c|c|c|c|}
\hline \multirow{2}{*}{$\begin{array}{l}\text { Nível de } \\
\text { concentradd } \\
\text { Concentrate } \\
\text { level }\end{array}$} & \multicolumn{4}{|c|}{$\begin{array}{c}\text { Categoria } \\
\text { Category }\end{array}$} & \multirow[t]{2}{*}{$\mathrm{CV}^{1}(\%)$} \\
\hline & $\begin{array}{c}\text { Novilhas } \\
\text { Heifers }\end{array}$ & $\begin{array}{c}\text { Machos } \\
\text { castrados } \\
\text { Steers }\end{array}$ & $\begin{array}{c}\text { Machos } \\
\text { não-castrados } \\
\text { Bulls }\end{array}$ & $\begin{array}{l}\text { Vacas } \\
\text { Cows }\end{array}$ & \\
\hline $25 \%$ & $14,63 \mathrm{Aa}$ & $16,25 \mathrm{Aa}$ & $\begin{array}{c}12,56 \mathrm{Ba} \\
23,62\end{array}$ & $11,53 \mathrm{Ba}$ & \\
\hline $50 \%$ & $10,70 \mathrm{Ab}$ & $12,37 \mathrm{Ab}$ & $20,49 \mathrm{Aa}$ & $21,17 \mathrm{Aa}$ & \\
\hline
\end{tabular}

${ }^{1}$ Coeficiente de variação (Coefficient of variation).

Letras maiúsculas comparam médias nas colunas e letras minúsculas, nas linhas. Médias seguidas de letras iguais não diferem $(P>0,05)$ pelo teste Tukey.

Capital letters compare means in the columns and small letters in the rows. Means, in a column or in a row, followed by the same letters do not differ $(P>0.05)$ by Tukey test.

A excreção de N-uréico está relacionada aos teores de uréia e/ou de PB das dietas (Moraes, 2003; Valadares et al., 1997). Considerando que as dietas eram isoprotéicas (aproximadamente $12 \%$ PB), não seriam esperadas as interações observadas.

Houve interação $(\mathrm{P}<0,05)$ níveis de concentrado $\times$ categorias animais para concentração de N-uréico no soro sanguíneo (Tabela 7). Observa-se que, para o nível de $25 \%$ de concentrado, não houve diferença $(\mathrm{P}>0,05)$ entre as categorias de Nelore. Contudo, para o nível de $50 \%$ de concentrado, as concentrações de N-uréico no soro sanguíneo foram maiores $(\mathrm{P}<0,05)$ para vacas e machos inteiros.

Avaliando cada categoria, nota-se que os machos nãocastrados e as vacas apresentaram maiores $(\mathrm{P}<0,05)$ concentrações de N-uréico sérico em dietas com $50 \%$ de concentrado. Considerando que a concentração sérica e a excreção de N- uréico estão relacionadas (Valadares et al., 1997) e, sendo as dietas isoprotéicas, a interação categorias $\times$ proporções de concentrado não seriam esperadas.

Entretanto, as concentrações de N-uréico no soro de animais mestiços (novilhos e vacas) não foram afetadas pelos níveis de uréia no concentrado, conforme Moraes (2003) e Silva et al. (2001), respectivamente. Segundo esses autores, esta resposta seria explicada pelo fato de os concentrados serem isoprotéicos. No entanto, Oliveira et al. (2001) encontraram aumento no N-uréico plasmático à medida que elevaram os níveis de uréia no concentrado das vacas e atribuíram esta resposta à redução da eficiência da utilização de amônia no rúmen.

\section{Conclusões}

O período de coleta de urina de 24 horas é suficiente para trabalhos com bovinos Nelore, independentemente de serem novilhas, machos castrados ou não-castrados ou vacas em lactação e das dietas conterem 25 ou $50 \%$ de concentrado, objetivando-se a avaliação da excreção urinária de creatinina, dos derivados de purina e da produção microbiana.

A coleta de amostra spot de urina também pode ser satisfatória, substituindo a coleta de 24 horas, para estimativa da produção de proteína microbiana em novilhas, machos inteiros ou castrados e vacas lactantes da raça Nelore.

\section{Literatura Citada}

CHEN, X.B.; GOMES, M.J. Estimation of microbial protein supply to sheep and cattle based on urinary excretion of purine derivatives- an overview of technical details. International feed research unit. Aberdeen: Rowett Research Institute, 1992. 21p. (Occasional publication).

CHEN, X.B.; MEJIA, A.T.; ORSKOV, E.R. Evaluation of the use of the purine derivative: creatinine ratio in spot urine and plasma samples as an index of microbial protein supply in ruminants: studies in sheep. Journal of Agricultural Science, v.125, p.137-143, 1995.

CHIZZOTI, M.L.; VALADARES FILHO, S.C.; VALADARES, R.F.D. et al. Excreção de creatinina em vacas. In: REUNIÃO ANUAL DA SOCIEDADE BRASILEIRA DE ZOOTECNIA, 41. 2004, Campo Grande. Anais... Campo Grande: 2004a. CDROM. Nutrição de ruminantes.

CHIZZOTI, M.L.; VALADARES FILHO, S.C.; VALADARES, R.F.D. et al. Excreção de creatinina em novilhos e novilhas. In: REUNIÃO ANUAL DA SOCIEDADE BRASILEIRA DE ZooteCniA, 41., 2004, Campo Grande. Anais... Campo Grande: 2004b. CD-ROM. Nutrição de ruminantes.

FLEMING, S.A.; HUNT, E.L.; RIVIERE, J.E. et al. Renal clearance and fractional excretion of eletrolytes over four 6-hour periods in cattle. American Journal Veterinary Research, v.52, n.1, p.5-8, 1991.

FUJIHARA, T.; ØRSKOV, E.R.; REEDS, P.J. et al. The effect of protein infusion on urinary excretion of purine derivatives in ruminants nourished by intragastric nutrition. Journal of Agricultural Science, v.109, p.7-12, 1987.

GONDA, H.L.; LINDBERG, J.E. Effect of diet on milk allantoin and its relationship with urinary allantoin in dairy cows. Journal of Dairy Science, v.80, p.364-373, 1997.

JOHNSON, L.M.; HARRISON, J.H.; RILEY, R.E. Estimation of the flow of microbial nitrogen to the duodenum using urinary uric acid or allantoin. Journal of Dairy Science, v.81, n.9, p.2408-2420, 1998.

MORAES, E.H.B.K. Suplementos múltiplos para recria e terminação de novilhos mestiços em pastejo durante os períodos de seca e transição seca-águas. Viçosa, $M G$ : Universidade Federal de Viçosa, 2003. 69p. Dissertação (Mestrado em Zootecnia) - Universidade Federal de Viçosa, 2003.

NATIONAL RESEARCH COUNCIL - NRC. Nutrient requirements of beef cattle. 7.ed. Washington: National Academic Press, 1996, 242p.

OLIVEIRA, A.S.; VALADARES, R.F.D.; VALADARES FILHO, S.C. et al. Produção de proteína microbiana e estimativas das excreções de derivados de purinas e de uréia em vacas lactantes alimentadas com rações isoproteicas contendo diferentes níveis de compostos nitrogenados não-proteicos. Revista Brasileira de Zootecnia, v.30, n.5, p.1621-1629. 2001.

$\varnothing$ RSKOV, E.R.; MACLEOD, N.A. The determination of minimal nitrogen excretion in steers and dairy cows and its physiological and practical implications. British Journal of Nutrition, v.47, p.625-636, 1982 
PEREZ, J.F.; BALCELLS, J.; GUADA, J.A. et al. Determination of rumen microbial-nitrogen production in sheep: a comparison of urinary purine excretion with methods using ${ }^{15} \mathrm{~N}$ and purine bases as markers of microbial-nitrogen entering the duodenal. British Journal of Nutrition, v.75, p.699-709, 1996.

RENNÓ, L.N.; VALADARES, R.F.D.; LEÃO, M.I. et al. Estimativa da Produção de Proteína pelos Derivados de Purinas na Urina em Novilhos. Revista Brasileira de Zootecnia, v.29, n.4, p.1223-1234, 2000.

RENNÓ, L.N.; VALADARES FILHO, S.C.; VALADARES, R.F.D. et al. Níveis de proteína na ração de novilhos de quatro grupos genéticos: estimativa da produção de proteína microbiana por intermédio dos derivados de purinas na urina. In: REUNIÃO ANUAL DA SOCIEDADE BRASILEIRA DE ZOOTECNIA, 40., 2003, Santa Maria. Anais... Santa Maria: 2003. CD-ROM. Nutrição de ruminantes.

RUSSEL, J.B.; O'CONNOR, J.D.; FOX, D.J. et al. A net carbohydrate and protein system for evaluating cattle diets: I. Ruminal fermentation. Journal of Animal Science, v.70, p.425-441, 1992.

STATISCAL ANALYSIS SYSTEM - SAS. System for Microsoft Windows. Release 8.2, Cary: 2001. CD ROM.

SILVA, R.M.N.; VALADARES, R.F.D.; VALADARES FILHO, S.C. et al. Uréia para vacas em lactação. 2. Estimativas do volume urinário, da produção microbiana e da excreção de uréia. Revista Brasileira de Zootecnia, v.30, n.6, p.1948-1957, 2001.
VALADARES, R.F.D.; GONÇALVES, L.C.; RODRIGUEZ, N.M. et al. Níveis de proteína em dietas de bovino. 4. Concentrações de amônia ruminal e uréia plasmática e excreções de uréia e creatinina. Revista Brasileira de Zootecnia, v.26, n.6, p.1270-1278, 1997.

VALADARES, R.F.D.; BRODERICK, G.A.; VALADARES FILHO, S.C. et al. Effect of replacing alfalfa with high moisture corn on ruminal protein synthesis estimated from excretion of total purine derivatives. Journal of Dairy Science, v.8, p.26862696, 1999.

VALADARES FILHO, S.C.; VALADARES, R.F.D. Teores de proteína em dietas de vacas de leite. In: SIMPÓSIO INTERNACIONAL DE GADO DE LEITE, 2., 2001, Lavras. Anais... Lavras: Universidade Federal de Lavras, 2001. 